\title{
O NEGRO NO BRASIL: UM PROBLEMA DE RAÇA OU DE CLASSE?'
}

Maria Nilza da Silva

\section{A democracia racial}

tão badalada democracia racial nos estudos clássicos e ainda presente na ideologia da sociedade brasileira apresenta uma explícita contradição com o não menos apologético processo de embranquecimento.

O Brasil diante do mundo apresentou-se como o modelo de relações raciais, o modelo de democracia racial, notadamente diante dos Estados Unidos que apresentam um racismo explícito, definido por Nogueira (1985) como preconceito de origem. Para ser discriminado racialmente basta que o indivíduo apresente "uma gota" de sangue negro. A transparência impactante dos Estados Unidos em relação ao racismo não apresenta possibilidades intermediárias, nem ambigüidades, refletindo o sistema dicotômico da sociedade norte-americana (Silva, 1994).

Park (1945), ao prefaciar o trabalho de Pierson, chega ao ponto de afirmar que a diferença entre o Brasil e os Estados Unidos em relação à questão racial é devida à "inocência paradisíaca" do povo brasileiro.

Essa pseudocaracterística do povo brasileiro foi muito defendida por intelectuais brasileiros, como Freyre (1963), Pierson (1945), Azevedo $(1955,1966)$ contribuindo pảa que os estudos de relações raciais fossem fundamentados apenas na presença dos grupos de cor, excluindo teoricamente a questão racial, com a negação da existência do racismo 
no Brasil e a afirmação somente da existência de grupos de cor. A sociedade estaria sedimentada nas relações de classe e não de raça. A ascensão social estaria ao alcance de todos, dependendo exclusivamente das potencialidades do indivíduo.

Essa perspectiva teórica retardou a devida discussão e a luta pela superação do racismo na sociedade brasileira. Ao analisar essa realidade, Guimarães (1995b) mostra quando o racismo brasileiro se torna semelhante, na prática, ao racismo norte-americano, começando a ser reconhecido também teoricamente entre os anos 40 e 60 .

"As perspectivas começaram a mudar apenas quando a segregação racial foi desmantelada nos Estados Unidos em consequência do movimento dos direitos civis. Somente então as desigualdades raciais passaram a ser claramente atribuídas à operação de mecanismos sociais mais sutis -a educação escolar, a seletividade no mercado de trabalho, a pobreza, a organização familiar, etc. A mudança de percepção da discriminação racial nos Estados Unidos alterou tanto a percepção do Brasil pelos anglo-americanos quanto o programa político anti-racismo. Desde então a denúncia das desigualdades raciais mascaradas em termos de classe social ou de status passaram a ser um item importante na pauta antiracista. Os racismos brasileiro e norte americano tinham se tornado mais parecidos entre si." (Guimarães, 1995b, p.29)

A questão racial no Brasil vem sendo aos poucos desvendada, embora seja nítida a resistência ao reconhecimento de sua importância, e a ausência de estudos explicada pela existência de uma democracia racial que se adapta à ideologia de defesa do embranquecimento como extermínio da raça negra. Schwarcz (1998) mostra que uma das dificuldades principais em reconhecer o racismo existente no Brasil é que a discriminação é remetida ao nível individual e não é assumida como elemento arraigado do cenário nacional. E, comumente, o preconceito racial é de certa forma refutado quando se trata de assumilo, embora amplamente praticado, gerando as conhecidas desigualdades sociais que nas últimas décadas estão sendo reveladas por sociólogos como Nelson do Valle Silva, Carlos Hasenbalg, Antonio Sérgio Guimarães, entre outros. 


\section{A discriminação racial}

Assumir o debate sobre o conceito de raça pressupõe determinada abertura para reconhecer o sistema de desigualdade estrutural da sociedade brasileira. No Brasil esse debate, que vem se realizando nas últimas décadas por alguns pesquisadores, foi precedido pelo estudo dos grupos de cor, concepção baseada nos fenótipos e na posição social do indivíduo, mas não havia uma discussão aprofundada do conceito. A principal justificativa para a negação da existência das raças no Brasil foi a "brandura" das relações entre brancos e negros e especialmente o processo de embranquecimento que apologeticamente foi encampado pela maioria dos nossos pesquisadores. Embranquecimento era visto como estágio de ascensão social do ex-escravo que, pela sua condição, era considerado inferior.

O estudo de grupos de cor de Pierson, (1945) e Azevedo, (1955, 1966) pressupõe uma ideologia racial que torna evidente a peculiaridade do racismo brasileiro cuja base está no extermínio da raça negra a partir do processo de branqueamento.

Segundo Schwarcz (1998)

"O antropólogo Roquete Pinto, como presidente do Congresso Brasileiro de Eugenia, que aconteceu em 1929, previa anos depois e a despeito de sua crítica às posições racistas, um país cada vez mais branco: em 2012 teríamos uma população composta de $80 \%$ de brancos e $20 \%$ de mestiços; nenhum negro, nenhum índio." (p.177)

Muitos pesquisadores não foram tão explícitos, mas o estudo dos grupos de cor pressupunha um processo de assimilação da população negra, excepcionalmente na tentativa de extirpar elementos inferiores do cenário nacional. Guimarães (1995a) refere-se ao desprezo pela abordagem do conceito raça, justificado este pela repulsa ao racismo ou mesmo porque o conceito carrega ideologias opressivas e a sua discussão poderia ratificar as desigualdades. Mas o autor expressa uma posição diversa dessas justificativas e manifesta o seu interesse em abordar a questão nas ciências sociais, pois 


\begin{abstract}
"aqueles que defendem a utilização do termo pelas ciências sociais enfatizam, em primeiro lugar a necessidade de empregar o conceito para demonstrar o caráter específico das práticas e crenças discriminatórias que fundamentam formas agudas de desigualdades raciais e, em segundo lugar, o fato de que, para aqueles que sofrem ou sofreram os efeitos do racismo não há outra alternativa senão reconstruir criticamente as noções dessa mesma ideologia - a vitimação é uma prova mesmo que o terreno conceitual que justificou práticas discriminatórias tem uma efetividade maior do que a de um círculo de giz." (Guimarães, 1995a, p. 46)
\end{abstract}

Hoje, a luta daqueles que reconhecem as desigualdades existentes no Brasil consiste justamente em defender a importância do estudo da questão racial e do conceito de raça. Enquanto este não for enfrentado por cientistas e pelos próprios negros numa forma de autoidentificação não será possível extirpar as desigualdades tão antigas no cenário nacional, especialmente mediante o seu processo de naturalização. Guimarães (1995b) refere-se às metáforas da questão racial abordadas na forma de classe, gênero e outros. Há uma máscara que esconde uma das questões fundamentais do cenário nacional: o racismo. Racismo que se traveste na ideologia da democracia racial, especialmente na defesa do embranquecimento como processo de integração da camada "inferior" à "superior" da sociedade. Contudo, nesse processo de embranquecimento poucos mestiços ascendem socialmente, a maioria permanece muito próxima da realidade dos pretos, com poucas exceções.

O Brasil sempre se orgulhou de sua "democracia racial", ideologia que vigora ainda hoje no senso comum. A principal justificativa para essa dificuldade em reconhecer o sistema de desigualdades baseado na questão racial está na inexistência de uma legislação racista. O Estado está oficialmente ausente da responsabilidade em face do racismo no Brasil (Andrews, 1998). A culpa pela existência do preconceito e da discriminação racial é transferida para o nível individual, atribuindo-a ao próprio negro por ocupar uma posição inferiorizada na sociedade.

Não se discutem as estratégias de desigualdades estruturais como educação, saúde, trabalho, renda. que compõem o cenário nacional (Guimarães, 1995b), havendo uma naturalização da situação. Sem o devido reconhecimento dessa realidade fica mais difícil lutar contra o 
processo de marginalização de quase $50 \%$ da população negra no Brasil. Schwarcz (1998, p.179) afirma que essa realidade

\begin{abstract}
"aparece de forma estabilizada e naturalizada, como se as posições sociais desiguais fossem quase um desígnio da natureza, e atitudes racistas, minoritárias e excepcionais: na ausência de uma política discriminatória oficial, estamos envoltos no país de uma boa 'consciência' que nega o preconceito ou reconhece como mais branda. Afirma-se de modo genérico sem questionamentos uma certa harmonia racial e joga-se para o plano pessoal os possíveis conflitos."
\end{abstract}

Essa naturalização das desigualdades que faz parte da teoria de muitos cientistas é também assimilada pela população e, talvez em alguns casos, pelos próprios negros que não têm possibilidade de visualizar objetivamente o contexto no qual estão inseridos. Ao nosso ver esse foi o principal problema, pois é manifesta a ausência da discussão racial ao longo de muitos anos no cenário científico no Brasil. Somente a partir da década de 50 , com os estudos patrocinados pela UNESCO, a venda dos olhos começa a cair e o Brasil passa a demonstrar semelhanças com os Estados Unidos no referente à questão racial e ao processo de exclusão do negro.

Uma das preocupações presentes no Brasil era a tentativa de demonstrar a sua distância em relação ao racismo dos Estados Unidos, porquanto aqui, supostamente, havia uma convivência pacífica entre brancos e negros e uma democracia racial que concedia chances a todos, baseando-se na suposta inexistência de raças no Brasil.

Nos Estados Unidos a questão racial está explícita na Legislação; no Brasil havia o reconhecimento apenas dos grupos de cor baseado na apresentação fenotípica, sendo esta uma das principais causas da dificuldade do reconhecimento do racismo em nosso país. Em relação aos Estados Unidos, Silva (1994, p.68) afirma:

"Na sociedade norte-americana, basta um indivíduo ter um ancestral negro para ser classificado como negro independentemente da suas características físicas aparentes. Esse tipo de regra que nem sempre se constitui na norma da sociedade norte-americana (...), obviamente reflete 
e reproduz uma rígida classificação racial e dicotômica: o indivíduo ou é branco ou é negro, sem possibilidades intermediárias, sem ambiguiidades."

Nos Estados Unidos o conceito de raça é evidente (Guimarães, 1995a) não é necessário discuti-lo. Não é o que ocorre no Brasil, uma vez que ainda hoje existem enormes dificuldades em apresentar o termo raça na pauta das discussões científicas. As pessoas "cultas" evitam abordar a questão, e, segundo Guimarães, a discussão é realizada por pessoas "não-refinadas", aquelas que tem um discurso de senso comum, como as vítimas de discriminação e os militantes de movimentos.

\section{O embranquecimento}

A ideologia do embranquecimento talvez seja uma das mais cruéis expressões do racismo no Brasil; primeiro, favorece a falta de identidade de uma raça imputando-lhe um outro modo de identificação que não corresponde a sua essência e, ainda, a ideologia do embranquecimento retira do cenário nacional a discussão da questão racial, visto que defende a idéia de ausência de raças e faz apologia da existência da cordialidade entre brancos e negros, excluindo a possibilidade de conflitos. Contudo, apenas o branco é sinônimo de valores positivos, desde os valores mais elementares do cotidiano, como aqueles relacionados ao status social. Se o negro quiser fazer parte do estrato superior deverá abdicar da sua raiz "inferior" e tornar-se "branco". O processo de branqueamento inclui negação das características não-nobres e adesão a valores dominantes. Essa ideologia previu o desaparecimento do negro enquanto raça, mas há um aumento do número de mestiços no Brasil, assim como um decréscimo no número de brancos e pretos.

Para Andrews (1998) ocorre um processo de "bronzeamento" da população e não de branqueamento como desejavam os pesquisadores, há algumas décadas. Esse processo de clareamento da raça negra com o aumento do número de mestiços não possibilitou para estes a alardeada ascensão social. Poucos mulatos ascendem, conforme afirma o autor em análise do Censo de 1940 e 1980 : 
"Os dados do censo deixam claro que durante os últimos cinquienta anos o Brasil experimentou um processo não de branqueamento, mas de bronzeamento. Entre 1940 e 1980, a população parda foi o grupo que cresceu mais rapidamente no país, ascendendo de $21,2 \%$ para $38 \%$ da população nacional. Durante o mesmo período os brancos declinaram de $63,5 \%$ para 54,2 porcento do total e os pretos de $14,6 \%$ para $5,9 \%$. $\mathrm{Se}$ os afro-brasileiros em mobilidade ascendente passaram para a categoria dos pardos e para a categoria racial dos brancos, isso não acontece em números suficientes para reverter esta tendência." (Andrews, 1998, p. 387)

Se o processo de embranquecimento é mantido também pela posição social que torna o negro "mais claro", esse mesmo processo não é acessível a todos, pois poucos negros e mestiços ascendem. E quando ascendem, o seu branqueamento não é total e, ainda que possuam status social de branco, nem todos os benefícios de que este dispõe estão ao alcance do negro. Ocorrem fortes restrições.

Figueiredo (1998), em seu trabalho sobre os profissionais liberais negros na cidade de Salvador, afirma que a ascensão social trouxe a estes a possibilidade de enegrecimento, de reconhecimento de sua real identidade, ao contrário do que é defendido por muitos ao afirmarem que a ascensão social clareia o indivíduo. A mesma sociedade que aposta no processo de embranquecimento para "extirpar" a "inferioridade" presente no negro não aceita o "embranquecido", pois este começa a ocupar posições que eram exclusivas do grupo dominante branco. O dinheiro foi mostrado como condição de branqueamento e a pobreza, de enegrecimento, como mostraram alguns estudiosos da questão (Azevedo, 1966; Pereira, 1948; Silva, 1994), mas o dinheiro também pode enegrecer quando a tentativa de integração do negro é barrada pela própria sociedade branca.

Figueiredo (1998) evidencia em seu trabalho outra dificuldade encontrada pelo negro que ascende, pois este é considerado exceção à regra; não há uma conscientização do potencial do negro, pois os poucos que conseguem uma mobilidade ascendente são vistos como exceção e como indivíduos isolados. O próprio negro também não conta com a solidariedade étnica como ocorreu com outras populações que apoiavam 
seus membros. O caso emblemático é o dos imigrantes, que chegaram ao Brasil, num projeto elitista de embranquecimento da sociedade e receberam investimentos do governo nacional (Andrews, 1998) para a sua integração e, ainda possuíam uma prática de apoio interno aos seus membros. O negro não encontrou nenhum apoio do governo, ao contrário, nem tampouco do seu próprio grupo étnico tendo que competir no mercado em condições de desvantagem com o branco. Por isso acredita-se que o processo de embranquecimento provavelmente seja um dos mais cruéis estágios do racismo brasileiro.

\section{O Preconceito racial}

Oracy Nogueira (1985) faz distinção de dois tipos de preconceito: o de marca e o de origem. $\mathrm{O}$ primeiro estaria relacionado às evidências externas, ao fenótipo do indivíduo e o outro relaciona-se ao pertencimento a um grupo racial, a uma etnia cujas características o distinguem de outros grupos. O autor afirma:

"Considera-se como preconceito racial uma disposição (ou atitude) desfavorável, culturalmente condicionada em relação aos membros de uma população, as quais se sentem como estigmatizados, seja devido à aparência, seja devido a toda ou parte da ascendência étnica que se lhes atribui ou reconhece. Quando o preconceito de raça se exerce em relação à aparência, isto é, quando toma por pretexto para suas manifestações, os traços físicos do indivíduo, a fisionomia, os gestos, o sotaque, diz-se que é de marca; quando basta a suposição de que o indivíduo descende de certo grupo étnico, para que sofra as conseqüências, diz-se que é de origem." (Nogueira, 1985, p.78)

O principal modelo de preconceito de origem, segundo Nogueira, foi o praticado nos Estados Unidos em contraposição à expressão de preconceito utilizada no Brasil, denominado como preconceito de marca, pois refere-se às características externas do indivíduo. Assim, assumir a existência do preconceito no Brasil não é tão difícil como reconhecer a discriminação racial. Muitos pesquisadores e a própria sociedade 
reconhecem a presença do preconceito racial, contudo, no nível individual e não no estrutural, que se reflete na discriminação racial.

Para Guimarães (1998), o preconceito, enquanto manifestação de uma crença prévia baseada em valores e qualidades presentes na idéia de raça, é mais reconhecido, contudo é condenado em nível intimista e restrito. Ainda não foi possível a opinião pública se convencer que a estrutura desigual da sociedade brasileira é motivada pela discriminação racial como um dos seus elementos fundantes. Segundo Schwarcz (1998, p.183)

"ninguém nega que exista racismo no Brasil, mas sua prática é sempre atribuída a 'outro'. Seja da parte de quem age de maneira preconceituosa, seja daquela de quem sofre com o preconceito, o difícil é administrar a discriminação e não o ato de discriminar."

A dificuldade e a recusa de discutir a questão racial motiva essa hipocrisia em relação à estrutura desigual do Brasil, pois que o evidenciado racismo se manifesta justamente no sistema de desigualdades de oportunidades (Guimarães, 1998) verificadas no Brasil através da educação, do trabalho, da renda etc. Esse sistema de desigualdades quase sempre foi visto como um problema de classes sociais. As desigualdades seriam extirpadas à medida que a proposta socialista vigorasse. Contudo, isso representa apenas mais um tipo de máscara que contribui para não se atingir a raiz do problema no Brasil, vale dizer, o racismo é promotor de desigualdades. A luta pela derrubada dessa estrutura pressupõe uma tomada de posição. Segundo Guimarães (1998, p.43)

"desafio mais crítico para aqueles que lutam contra o racismo no Brasil está justamente em convencer a opinião pública do caráter sistemático e não-casual destas desigualdades; mostrar a sua reprodução cotidiana através de empresas públicas e privadas, através de instituições da ordem pública como a polícia e os sistemas judiciário e correcional; através das instituições educacionais de saúde pública. assim pode-se esperar levantar o véu centenário que encobre as dicotomias elite/povo, branco/negro na sociedade brasileira." 


\section{A problemática do estudo da questão racial no Brasil}

Autores como Donald Pierson, Thales de Azevedo, entre outros, ao discutirem a questão dos negros na sociedade brasileira referiram-se a estes como membros de grupos de cor, em contrapartida a uma tendência que os antecedeu, das teorias racistas degenerativas baseadas na biologia. As teorias preocupadas com a presença do negro na sociedade procuraram destacar a classe em detrimento da raça. A justificativa é que a situação do negro na sociedade estaria baseada na sua cor, portanto a justificativa para os baixos níveis sociais era a inferioridade baseada na cor mais escura que lembra a escravidão, e, à medida que houvesse um processo de miscigenação com o embranquecimento do negro, ele teria a possibilidade de ascender socialmente. No prefácio à edição brasileira da obra de Pierson, Ramos (1945) afirma que

“...o negro de cor mais escura parece ser o que emergiu mais recentemente da escravidão e por isso ocupa ainda os degraus mais baixos da vida econômica e social, sofrendo com mais intensidade o preconceito de classe. O 'preconceito de cor', a que alude Frazier, reduzir-se-ia, assim, também a um preconceito de classe, no sentido de Pierson. (Ramos, 1945, p. 24)

Durante longo período da história das relações raciais no Brasil ocorreu a confusão entre a discriminação baseada no racismo e a discriminação baseada na classe social. Foi mais cômodo, diante de um projeto de embranquecimento resolver as questões teóricas referentes às diferenças raciais no Brasil (Pierson, 1945), com base na apologia dos grupos de cor e não da raça. Dessa perspectiva o principal responsável pela inferioridade do negro é ele mesmo. Há um destaque, na literatura para o mulato que ascendeu socialmente, lembrando-se que quanto mais clara a sua cor, maiores chances de ascender socialmente. É o projeto assimilacionista que buscou retirar do negro a sua origem, ainda que para isso ele tivesse que abdicar da própria identidade.

Guimarães (1995a), em estudos recentes, procura questionar essa postura que marcou a história dos estudos das relações raciais no Brasil, numa determinada época, e propõe uma nova forma de estudo 
baseada no resgate do conceito de raça e dos fundamentos das desigualdades sociais, uma vez que o conceito de classe e posição sócio-econômica não dão conta da complexidade. A preocupação era desvincular grupos de cor da noção de raça. Contudo, o autor afirma que a diferenciação fenotípica, com reflexos sociais pressupõe uma arraigada ideologia racial.

"Com o declínio do prestígio das teorias racialistas no Brasil, a partir dos anos 40, desaparece - pelo menos no nível do discurso e da consciência os apelos a teorias racialistas na definição da cor, tal como a teoria que explicava pela reversão a fixação de caracteres somáticos, fenótipos e de caráter. Os grupos de cor passam a ser pensados em termos de senso comum como enquadrando apenas características fenotípicas, desaparecendo a sua explicitação racialista e sustentandose apenas numa ideologia da espontaneidade e obviedade de nossas percepções cromáticas e físicas." (Guimarães, 1996, p. 144)

A centralidade fenótipica e não racial propriamente dita justificou a importância da classe em detrimento da problemática racial no Brasil. Quanto maior a posição social, mais embranquecido o indivíduo se torna. Conforme abordado anteriormente, outra perspectiva aparece no estudo de Figueiredo(1998) sobre os profissionais liberais negros de Salvador, que apresentam uma forte identidade étnica ao ascenderem socialmente, contrapondo à idéia ${ }^{2}$ de que quanto maior a ascensão social maior o embranquecimento do indivíduo negro.

Experiências de negros que tiveram ascensão social apresentam perspectiva semelhante, em contraposição ao senso comum da ideologia do embranquecimento diante da ascensão social. A experiência de mulhere ${ }^{3}$ negras que tiveram mobilidade social ascendente através da educação formal demonstram forte identidade étnica ${ }^{4}$, embora muitas delas poderiam não se auto-identificar como negras por causa da pele clara, mas ao contrário, reafirmam a identidade baseada na própria ascendência e especialmente na consciência adquirida.

As trajetórias de vida dos mestiços apresentam características assemelhadas às dos pretos. $\mathrm{O}$ processo de embranquecimento enaltecido ao longo da história dos estudos das relações raciais, como 
elemento de ascensão social - teve pouco resultado nessa perspectiva. São poucos os mestiços que efetivamente tiveram ascensão social.

Andrews (1998) reconhece a existência de diferenças raciais entre o grupo mestiço ${ }^{5}$ e o preto, mas em relação ao grupo branco, essas diferenças diminuem o seu impacto devido à evidente distância em relação a este último. Andrews enfatiza aspectos comuns entre pardos e pretos, mas não deixa de considerar a existência de uma dicotomia quando se refere ao relacionamento entre estes, visto que esta revela, com precisão, a estrutura social do Brasil do século $\mathrm{XX}$, e reconhece:

"É verdade que todos os pardos têm mais probabilidade do que os pretos de conseguir essa mobilidade: mas os benefícios da preferência racial e do progresso social chegam apenas para uma pequena proporção do grupo racial pardo, a maioria deles continuando a viver e a trabalhar em condições indistinguíveis daquelas de seus concidadãos pretos." (Andrews, 1998, p. 391)

\section{Uma questão de raça ou de classe?}

Muitos ainda hoje acreditam que as desigualdades sociais que fazem parte do cenário da sociedade brasileira é uma questão de classe social. Nas últimas décadas, vários estudiosos da sociedade procuram convencer a opinião pública que o reducionismo econômico está superado, numa tentativa de demonstrar as reais interferências dos problemas relacionados a gênero, raça, religião, entre outros, na questão da desigualdade.

A ideologia de que as distâncias sociais são motivadas apenas pela questão econômica é fortemente sustentada pela bandeira da falsa democracia racial. Está arraigada no pensamento social brasileiro a idéia de que o pobre é o único responsável por sua posição social, assim como o negro em relação à pobreza, remetendo ao injustiçado a responsabilidade pela própria posição.

Os estudos que fundamentam a importância da classe em relação à raça e produzem influências no pensamento contemporâneo põem sua raiz, desenvolvimento e difusão em estudiosos das relações raciais. É o 
caso de Donald Pierson (1945) e Thales de Azevedo (1955, 1966). Pierson, em seu estudo sobre relações raciais na Bahia, salienta a diferença entre as relações raciais no Brasil e aquelas dos Estados Unidos. Para ele, na sociedade brasileira predominava certa cordialidade entre os brancos e os negros, sendo que as distâncias sociais entre os dois grupos fundamentavam-se, sobretudo, numa questão de classe e não de raça. A posição social inferior do negro era justificada pela recente passagem de uma conjuntura de escravidão para a liberdade. Portanto, necessitava de mais tempo para que as desigualdades fossem resolvidas. Mas a responsabilidade em superar a condição inferior dependia, segundo Pierson, da própria habilidade do negro. Se ele fosse capaz sairia daquela realidade, que o segregava também espacialmente.

"Assim, embora a Bahia esteja dividida de modo definido em classes 'superiores' e 'inferiores', que ocupam áreas bastante distintas da cidade e estas classes e divisões geográficas tendam a corresponder aproximadamente às divisões de cor, pode-se notar algumas exceções importantes, cujo aparecimento indica classe [mais] que raça, como base da organização social." (Pierson, 1945, p. 78)

Os raríssimos exemplos de exceção de negros que conseguiram ascender socialmente se transformaram em motivo para desconsiderar a importância da desigualdade racial presente na sociedade baiana. Azevedo (1966) justifica a importância da classe no estudo que realiza sobre os grupos de prestígio, em detrimento da cor e relaciona a questão aos casamentos inter-raciais.

"Como o conceito de 'cor' envolve elementos antropofísicos e sociais e as relações raciais são carregadas de notas de classe, toda a união heterocrônica consiste em um simultâneo rompimento de preconceito de 'cor' e das distinções e distâncias sociais derivadas da posição e da consciência de classe.”(Azevedo, 1966, p.8)

A questão econômica para Pierson e Azevedo é determinante; contudo, os autores não questionam as diferenças de oportunidades no processo de conquista de status social, embora Pierson reconheça 
que os negros tenham que lutar mais para a conquista de posições semelhantes às dos brancos, procura, no entanto, justificar a luta desigual, pois para ele o negro parte do estrato social mais baixo e da descendência escrava recente e remete a responsabilidade pela superação de posições inferiores ao próprio negro.

"Na determinação do 'status' social, a competência do indivíduo tende a superar a origem racial." (Pierson, 1945, p. 240)

Maria Isaura Pereira de Queiroz (1978) reconhece a existência de duas correntes no estudo da questão racial no Brasil. A primeira que remete as diferenças e desigualdades sociais ao problema das classes; a existência do preconceito seria, pois, um problema ameno, visto que baseada na posição econômica. A outra postura envolve uma problemática maior, pois considera que as diferenças raciais são o fundamento das posições desiguais e injustas em que o negro se encontra. Nessa perspectiva, haveria uma segregação racial que remete ao sistema de castas. Queiroz salienta mais a classe que a raça. Para ela, à medida que os problemas econômicos fossem resolvidos, os negros não teriam problemas raciais.

\footnotetext{
'Não existe, no Brasil, uma dualidade étnica - o termo 'dualidade' tomado em sua legitima expressão que é a de dois grupos étnicos irredutíveis um ao outro. Existem preconceitos, mas estes são regidos em sua expansão ou em sua amenização pelas necessidades do mercado de trabalho de uma sociedade de classes. No momento em que a ascensão da coletividade negra se materializa, por constituírem os negros uma mão de obra indispensável, os preconceitos étnicos (atitudes desfavoráveis contra um grupo étnico) ficam em baixo e não se tornam obstáculos à ascensão.) No momento em que a ascensão é freada pelas características conjunturais do mercado de trabalho, os preconceitos são usados para justificar a existência das barreiras então opostas." (Queiroz, 1978, p. 259)
}

Nessa perspectiva, a questão racial emerge quando o mercado está em crise, e, ao ser superada, já não se levantará o preconceito racial como bandeira que justifique as desigualdades sócio-econômicas. 
Cientistas sociais, com considerada influência na formação do pensamento social brasileiro, são responsáveis pela difusão da idéia de classe ao invés de raça, que se encontra arraigada na sociedade contemporânea, o que dificulta levantar a problemática racial como objeto de estudos científicos.

Para Oliveira, Porcaro e Costa (1985), Florestan Fernandes liderou uma corrente na década de 50 e 60 que prevê a relação entre classes e raças. Reconhece que o processo de transformação sócio-econômicoindustrial que ocorre no mundo, e na sociedade brasileira especificamente, não atende aos anseios de todos igualmente. Existe a problemática racial, pois negros, que no século passado saíram do regime de escravidão para a liberdade, continuam vivendo sob um regime de casta. Foram excluídos do mundo do capital. Contudo, acredita o citado autor que, embora haja problemas raciais, estes serão superados quando forem eliminadas as classes. Essa perspectiva é fundamentada na proposta marxista para solução dos problemas sociais. Embora reconheça que o negro convive com um problema duplamente qualificado, enquanto raça e como trabalhador, Florestan pensa que o problema racial não é fundamental, porquanto virá a transformar-se, com a abolição das classes.

"A interação de raça e classe existe objetivamente e fornece uma via para transformar o mundo, para engendrar uma sociedade libertária e igualitária sem raça e sem classe, sem dominação de raça e sem dominação de classe. O nosso debate e o fim do nosso movimento é esse. No Brasil não se pode proclamar simplesmente: 'proletários de todo o mundo, uni-vos'. A nossa bandeira não arca com as contingências do eurocentrismo inerente ao capital industrial emergente. Ela se confronta com o sistema de poder mundial de termo financeiro e oligopolista (ou monopolista). E que nos dita: 'proletários de todas as raças do mundo, uni-vos.' A conseqüência é a mesma: eliminar a classe como meio de exploração do trabalho e de preservação das desigualdades e iniqüidades que ela determina, inclusive as raciais. Isso significa em nossa sociedade, proletários, negros e brancos, uni-vos para forjar a sua sociedade, não a dos capitalistas. O que não é simples, porque o negro deve emanciparse coletivamente em termos de sua condição racial e como força de trabalho." (Fernandes, 1989, p.12) 
Segundo o autor, para que houvesse democracia racial no Brasil, era necessário o regime socialista. Desta forma, as diferenças seriam niveladas, Até mesmo as raciais, pois todos os potenciais presentes na sociedade seriam aproveitados. Florestan considerava que o talento mais desperdiçado no Brasil era o talento do negro. As mudanças nas relações de classe conduziriam às transformações nas relações raciais. Contudo, pesquisadores contemporâneos prevêem que ainda que a questão das classes sociais fossem resolvidas e a sociedade fosse econômica e socialmente igualitária em relação ao contingente de trabalhadores, a questão racial não estaria resolvida tão simplesmente.

Ianni (1978) reconhece a existência de diferenças entre o trabalhador branco e o negro. Este, para desfrutar de condições semelhantes às do branco teria que se esforçar muito mais, deveria ser melhor que o trabalhador branco. Para Ianni, assim como para Fernandes, o negro é duplamente desfavorecido e vai percebendo o processo desfavorável em que está inserido tanto em relação à classe quanto em relação à raça.

“...o negro toma consciência de sua dupla alienação: como raça e como membro de classe. Nesse sentido, para reduzir ou eliminar as condições de alienação, da sua condição duplamente subalterna, o negro é levado a pôr-se diante de si mesmo e do branco como membro de outra raça e membro de outra classe. Enquanto membro de classe, está mesclado com membros de outras raças e precisa lutar a partir dessa condição. Nesse contexto, raça e classe subsunem-se recíproca e continuamente, tornando mais complexa a consciência e prática políticas do negro." (Ianni, 1978, p. 80)

Oliveira, Porcaro e Costa (1985), ao analisarem a postura de Fernandes e Inani, acreditam que para estes o problema racial representa uma máscara do conflito de classes e, principalmente que o "conflito racial se transformará em conflito de classe." A raça, nessa corrente de pensamento, é um elemento secundário. O que importa é resolver os conflitos das classes e a partir daí poderá ocorrer a proclamada democracia racial. 


\section{O processo de segregação}

Segundo Hasenbalg (1979), fica cada vez mais difícil justificar as desigualdades sociais experienciadas pelos negros na atualidade através da sua origem social, pois estes são os mais prejudicados na sociedade brasileira. A problemática racial é determinante, nesse caso.

O fim do regime escravocrata poderia ter significado uma libertação social do negro, mas este continuou preso àquele sistema quando o excluíram do processo de transformação da sociedade brasileira. A sociedade construída, ao longo de quase quatro séculos, pelo trabalho do negro, quando muda de sistema joga o seu artífice à sua margem e a maioria da população negra ainda se encontra no lugar que a sociedade lhe concedeu. Segundo Andrews (1998), o governo gastou milhões de dólares com os imigrantes, mas não investiu absolutamente nenhuma quantia com a população negra. Ao contrário, explicitamente a excluiu da possibilidade de exercer a cidadania. Primeiro, com a República, proibiu o voto aos analfabetos e para os negros que se constituíam a maioria destes e, posteriormente, não permitiu ao negro ingressar no mercado de trabalho, especialmente o homem negro. No caso da mulher, esta continuava a servir às casas dos patrões brancos como empregadas domésticas, babás e concubinas. À mulher negra restou o pesado fardo de manutenção dos companheiros, quando tinha, e dos filhos.

O negro não simbolizava o progresso que a sociedade no Brasil queria representar. Segundo Queiroz (1978, p.238):

"A abolição da escravatura modificou profundamente a estrutura sócioeconômica do país, cuja definição fundamental fora até então a existência das relações senhor-escravo. É interpretada geralmente como rejeição dos antigos escravos para a periferia da estrutura sócio-econômica, passando a formar um sub-proletariado miserável, sobretudo nas cidades do sul do país. Nesta região ampliava-se a imigração européia desde a expansão cafeeira, fazendo aumentar rapidamente uma mão-de-obra ocidental, o que não se dava com os antigos escravos. Ora, as grandes cidades brasileiras foram submetidas a um processo marcante de 'aburguesamento' no decorrer do século XIX. Os antigos escravos não apresentando as características requeridas para se adaptarem às exigências 
urbanas novas, ligadas principalmente à expansão da administração pública, dos serviços, do comércio, foram rejeitados para uma camada social inferior à dos imigrantes brancos; dificilmente podia entrar em concorrência com estes no mercado de trabalho urbano, para o qual não estavam preparados do ponto de vista da instrução e de conhecimentos gerais, não estando assim aptos a ganhar eficientemente sua vida numa sociedade transformada e em plena expansão."

Na história do negro no Brasil é difícil constatar onde a injustiça praticada está mais acirrada. Esta é indiscutível quando se refere ao período de escravidão mas, após a "abolição", qual foi verdadeiramente o benefício concedido ao negro, se ainda hoje está relegado aos estratos mais baixos da escala social?

Fernandes (1972) afirma que diante das transformações da sociedade, o negro tenderia paulatinamente a ser absorvido pelo sistema de classes sociais, mas reconhece que o processo ocorre demasiado lento contribuindo para a sua permanência, com poucas exceções, nos porões de pobreza social.

"As contradições sociais herdadas do passado e que entravam a integração do 'negro' e do 'mulato' à ordem social competitiva emergente não interessavam senão à população de 'cor', de resto a única diretamente prejudicada por aquelas contradições.” (Fernandes, 1972, p. 31)

Somente após 1945, segundo Fernandes, a sociedade se torna um pouco mais tolerante em relação à mão-de-obra do negro. Isso se deve ao constante crescimento econômico. Mas, ainda diante da necessidade do trabalho do negro, este ocupou sempre os postos menos privilegiados, e o pior, nessa trajetória desigual e injusta, é que diante da posição social ocupada pelo negro, sempre lhe foi atribuída a responsabilidade, não se considerando a estrutura social e internalizando-se a idéia de que, se o negro não venceu, é porque lhe faltou capacidade. A difusão desta idéia constitui um dos maiores males à dignidade da população negra, uma vez que a classe dominante conseguiu que parte considerável dos negros aderissem a essa postura ideológica. É diante desse contexto adverso que o negro luta pela sua ascensão social. 


\title{
- Ascensão social e embranquecimento
}

O estudo da ascensão social do negro parece carregar uma contradição e um questionamento sobre a pertinência deste tema, visto que a maioria dos negros brasileiros ainda não saíram do jugo da pobreza e do lugar marginal que a sociedade lhes reservou. A justificativa da temática está justamente no bojo desta contradição, em especial quando a ascensão social do negro, ao longo de muitos anos de estudo, resultou de um processo de branqueamento. $\mathrm{O}$ negro deveria autonegar-se enquanto raça para ser aceito na sociedade dominante. Para Azevedo (1966, p.33), o negro embranquece quando ascende:

\begin{abstract}
"A identificação do grupo superior com os brancos é expressa hoje com sentenças como 'quem tem dinheiro é branco' desde que o conceito de branquidade é simultaneamente relativo ao tipo físico e à posição social. Uma pessoa de traços negróides atenuados pode ser considerada branca se é rica ou tem papel de relevo. (...) um preto que alcança uma posição elevada vem a ser tratado como 'escuro', como 'roxo'; até mesmo 'moreno', nunca como 'preto' e muito menos como 'negro', que é um termo depreciativo e ofensivo."
\end{abstract}

Se o negro quisesse sair da marginalidade deveria autonegar-se enquanto raça, e para tornar-se símbolo de prosperidade, beleza, riqueza e de valores positivos, embranquecer-se. Mas esse processo sempre foi relativo e limitado, pois a mesma sociedade que impõe tal condição também "nega" o embranquecido, manifestando o preconceito e a discriminação tanto no cotidiano do negro pobre quanto no daqueles que ascenderam e conquistaram um status mais elevado na sociedade; sempre há restrições manifestas nas diversas expressões da discriminação racial, no trabalho, na educação, no rendimento inferior, na segregação espacial etc.

O mulato, segundo Pierson (1945), teve mais chances de ascender, pois que quanto mais claro, maiores se julgavam as suas capacidades. O potencial em manifestar valores positivos, considerados valores brancos, era visto como algo inerente ao indivíduo de pele clara, ou seja 
ao mulato, devido a sua aproximação com a cor branca. Nessa persperctiva, aparece com destaque a violência simbólica a que o negro é submetido, pois tudo que remete à sua origem é considerado negativo. Hasenbalg expressa os efeitos desse tipo de violência em relação às oportunidades de ascensão social:

\begin{abstract}
"No que diz respeito ao racismo, além dos efeitos dos comportamentos discriminatórios, uma organização social racista também restringe a motivação e o nível de aspirações das pessoas não brancas. Quando se consideram os mecanismos que atribuem a mobilidade social ascendente dos não-brancos, às práticas discriminatórias dos brancos (sejam elas sutis ou abertas) devem ser acrescentados os efeitos de bloqueio derivados de internalização de uma auto-imagem desfavorável por parte daqueles que não são brancos. Desta forma, as práticas discriminatórias, a evitação de situações discriminatórias e a violência simbólica perpetuados contra os não-brancos se reforçam mutuamente, fazendo com que normalmente negros e mulatos regulem suas aspirações de acordo com o que é culturalmente imposto e deferido como o 'lugar apropriado' para pessoas de 'cor.' (Hasenbalg, 1979, p. 167)
\end{abstract}

A hipocrisia manifesta na negação do racismo e na difusão de valores negativos como sinônimo de negritude violenta toda a trajetória de um povo, ao qual foi negado o direito de sonhar e aspirar a condições dignas de cidadania. As poucas exceções que conseguem furar os bloqueios da pobreza sofrem as conseqüências de uma sociedade que não aceita o negro, especialmente quando este representa um elemento na concorrência de status social.

Bastide (1971) refere-se a Donald Pierson para quem o-negro não poderia representar ameaça enquanto concorrente do branco, visto ser este o seu provedor, e o negro ser considerado como um dependente do branco. Segundo Bastide, no entanto, essa situação não seria confirmada em uma região como São Paulo em que o negro poderia ter melhores possibilidades de ascensão, principalmente mediante a instrução. Afirma:

“... onde a facilidade de instrução, as oportunidades da industrialização, o enfraquecimento do controle dos brancos devido à dispersão das famílias 
tradicionais numa imensa cidade, permitiram a ascensão dos negros já não como indivíduos isolados, mas como grupo social. A partir desse momento (o branco) começou a sentir-se ameaçado nos seus postos de direção e mando." (Bastide, 1971, p.188)

Essa ascensão grupal, a que se refere Bastide, é confrontada com as outras posições de estudiosos da questão racial, para os quais ocorre ascensão individual e não grupal; não existe uma "classe média" negra, mas indivíduos negros que pertencem a estratos médios. Muitos manifestam a solidão social pela dificuldade em interagir com seus pares raciais. Ângela Figueiredo, no estudo sobre profissionais liberais negros de Salvador, mostra que estes não se sentem embranquecidos, ao contrário, sofreram um processo de enegrecimento. À medida que ascendem socialmente vão se auto-percebendo negros. Visto que, a classe dominante lhes mostra que são negros e que, portanto, deveriam ocupar outro espaço na sociedade, ratificando a posição de inferioridade.

Finalmente, a ascensão social de indivíduos negros é vista como exceção particularmente porque esta depende de esforços que, conforme o consenso da sociedade, o negro não realiza, atribuindo-se apenas às qualidades individuais o processo de superação da marginalidade. Para essa ideologia o sucesso depende de esforços e virtudes individuais (Mills, 1976). O êxito pessoal está acima da estrutura social. Nesse sentido a ideologia da inferioridade do negro ganha potencial maior, pois o indivíduo que ascendeu representa aquele que optou por aderir aos valores considerados brancos. Essa ascensão individual manifesta a falta de solidariedade étnica que está presente em outros povos (Figueiredo, 1998). Por isso, como vimos, estudiosos das questões raciais afirmam não existir uma classe média negra, mas indivíduos dispersos.

A ascensão individual pode representar algo não confortável para os negros, porque há uma solidão étnica. Nem sempre o poder aquisitivo representa aceitabilidade por parte do branco. É nesse sentido que, para Weber, a questão econômica não possui um fim em si mesmo, a posição social do indivíduo é determinada pelo pertencimento ao grupo de status. 
Muitas vezes pode ocorrer uma tolerância, mas não a integração social. O negro que ascende tem que conviver com outro elemento que geralmente pode incomodar, pois é exceção à regra e causa surpresa se ocupa posições privilegiadas (Bastide, 1971).

\section{Notas}

${ }^{1}$ Este artigo faz parte do primeiro capítulo da dissertação de mestrado Mulheres Negras: o preço de uma trajetória de sucesso, defendida em 13 de maio de 1999 na PUC/SP.

${ }^{2}$ Ver: Souza, Neusa Santos (1983) Tornar-se negro. Rio de Janeiro, Graal.

${ }^{3}$ Ver: Silva, Maria Nilza da (1999) Mulher negra: O preço de uma trajetória de sucesso. São Paulo. Dissertação (Mestrado) PUC/SP.

${ }^{4}$ Considera-se étnico o grupo com identidades socio-culturais comuns, independentes das características fenótipicas.

${ }^{5}$ Considera-se mestiço aquele denominado mulato, pardo, moreno.

\section{Referências Bibliográficas}

ANDREWS, George R. Negros e brancos em São Paulo 1888 - 1988. São Paulo: Edusc, 1998

AZEVEDO, Thales de. As elites de cor: um estudo de ascensão social. São Paulo: Ed. Nacional, 1995.

AZEVEDO, Thales de. Cultura e situação racial no Brasil. Rio de Janeiro: Civilização Brasileira, 1966.

BALIBAR, Etienne; WALLERSTEIN, Immanuel. Race, Nation, Classe: les identité ambiguës. Paris: La Découverte, 1990

BARBER, Bernard. Estratificação social. In: SILLS, David (org.) Enciclopédia Internacional de Las Ciências Sociales. Madrid: Aguilar, 1974.

BASTIDE, Roger e FERNANDES, F. Brancos e Negros em São Paulo. 3 ed. São Paulo: Ed. Nacional, 1971. 
CARDOSO, Fernando H. e IANNI. Cor e mobilidade social em Florianópolis São Paulo: Ed. Nacional, 1960.

COSTA PINTO, Luiz Aguiar. O negro no Rio de Janeiro. São Paulo: Ed. Nacional, 1952.

FERNANDES, Florestan. A integração do negro na sociedade de classes. São Paulo: Ática, 1978.

FERNANDES, Florestan. O negro no mundo dos brancos. São Paulo, Difusão européia, 1972.

FERNANDES, Florestan. O negro no mundo dos brancos. São Paulo: Difusão Européia do Livro, 1972.

FERNANDES, Florestan. Significado do protesto negro. São Paulo: Autores Associados, 1989

FIGUEIREDO, Ângela. Novas elites de cor. Estudos sobre profissionais liberais negros de Salvador. Salvador, 1998. Dissertação (mestrado), UFBA.

FRANÇA, Bárbara H. Nova classe média ou novo proletariado?. São Paulo em Perspectiva, v. 8, n. 1, p. 44-50, jan/mar 1994.

FREYRE, Gilberto. Casa grande e senzala. 12. ed., Brasília: Unb, 1963.

FREYRE, Gilberto. Sobrados e mucambos. 4.ed. Rio de Janeiro: J. Olímpio, 1968. T.2

GOFFMAN, Erving. Estigma: notas sobre a manipulação da identidade deteriorada. Rio de Janeiro: Zahar, 1982.

GUIMARÃES, Antônio Sérgio (B). Racismo e Anti-racismo no Brasil, In: Novos Estudos CEBRAP, São Paulo: p. 26-44, nov. 1995.

GUIMARÃES, Antonio Sérgio. As elites de cor e os estudos das relações raciais. São Paulo em Perspectiva, São Paulo, v. 8, n. 2, p. 67-83, out/nov. 1996.

GUIMARÃES, Antônio Sérgio. Cor, classes e Status nos estudos de Pierson, Azevedo e Harris na Bahia: 1940-1960. Raça, Ciência e Sociedade, Rio de Janeiro: FIOCRUZ, p. 145-178, 1996.

GUIMARÃES, Antônio Sérgio. Preconceito e discriminação: queixas e ofensas no tratamento desigual dos negros no Brasil. Salvador: Novos Toques, 1998.

GUIMARÃES, Antonio Sérgio (A). Raça, racismo e grupos de cor no Brasil. Estudos Afro-Asiáticos, Rio de Janeiro: n. 27, p. 45-63, 1995. 
HASENBALG, C. e SILVA, N. do V. Educação e diferenças raciais na mobilidade ocupacional no Brasil. Caxambu: Trabalho apresentado na XXII ANPOCS, 1998.

HASENBALG, C. e SILVA, N. do V. Estrutura social, mobilidade e raça. Rio de Janeiro, Iuperj, 1988.

HASENBALG, Carlos. Discriminação e desigualdades raciais no Brasil . Rio de Janeiro: Graal, 1979

"Entre o mito e os fatos: racismo e relações raciais no Brasil". Dados - Revista de Ciência Sociais, Rio de Janeiro, v. 38 , n. 2, p. 355 $374,1995$.

$35,1987$.

Debate. Cadernos de Pesquisa, São Paulo: n. 63, p. 30-

HUTCHINSON, Bertran. Mobilidade e trabalho: um estudo na cidade de São Paulo. Rio de Janeiro: INEP, 1960.

IANNI, Octávio. As metamorfoses do escravo. 2 ed. Breve e aumentada, São Paulo: Hucitec, 1980.

IANNI, Octávio. Escravidão e racismo. São Paulo: Hucitec, 1978.

LIPSET, Seymour M. Classe social. In: Sills, David (org.) Enciclopédia Internacional de Las Ciências Sociales. Madrid: Aguilar, 1974. Vol. 4.

MOURA, Clóvis. Sociologia do negro no brasileiro. São Paulo, Ática, 1988.

NOGUEIRA, Oracy. Tanto preto quanto branco: estudo de relações raciais. São Paulo: T.A. Queiroz, 1985.

OLIVEIRA, L.E.; PORCARO e COSTA, T.; O lugar do negro na força de trabalho. Rio de Janeiro, IBGE, 1985.

PARK, Robert. Prefácio. In: PIERSON, Donald. Brancos e pretos na Bahia: um estudo de contato racial. São Paulo, Ed. Nacional, 1945.

PASTORE, José. Desigualdade e mobilidade social no Brasil. São Paulo: Edusp, 1979.

PIERSON, Donald. Brancos e pretos na Bahia: estudo de contato racial. São Paulo, Ed. Nacional, 1945.

PINSKY, Jaime. A escravidão no Brasil. 12.ed. São Paulo: Contexto, 1993.

PINSKY, Jaime (org.) 12 faces do preconceito. São Paulo: Contexto, 1999. 
QUEIROZ, Maria Isaura P. de. Cultura, sociedade rural e sociedade urbana no Brasil. Rio de Janeiro: LTC, 1978.

RAMOS, Arthur. In: PIERSON, Donald. Brancos e pretos na Bahia: um estudo de contato racial. São Paulo: Ed. Nacional, 1945.

SCHWARCZ, Lilia M. Nem preto nem branco, muito pelo contrário: cor e raça na intimidade. In: História da Vida Privada. São Paulo, Cia das Letras, 1998.

SILVA, Nelson do. Uma nota sobre raça social no Brasil. In: Estudos dos AfroAsiáticos, Rio de Janeiro, n. 26, p. 67-80, 1994.

SILVA, Nelson e HASENBALG C. Relações Raciais nò Brasil Contemporâneo. Rio de Janeiro: Rio Fundo, 1992.

SKIDMORE, Thomas. O Brasil visto por fora. Rio de Janeiro: Paz e Terra, 1994.

SOUZA, Neusa Santos. Tornar-se negro: ou as vicissitudes da identidade do negro brasileiro em ascensão social. Rio de Janeiro: Graal, 1983.

STAVENHAGEM, Rodolfo. "A questão da estratificação social e das classes sociais. In: VVAA (org.) Estrutura de classes e estratificação social. Rio de Janeiro: Zahar, 1977.

WEBER, Max. Classe, status, partido. In: VVAA (org.) Estrutura de classes e estratificação social. Rio de Janeiro: Zahar, 1977.

\section{Resumo}

Este artigo procura realizar uma revisão bibliográfica na tentativa de recuperar a clássica discussão sobre classe social, raça, ideologia do embranquecimento/ enegrecimento e a questão do sucesso individual. A partir da década de 70 , com a ascensão dos movimentos negros organizados, ocorrem avanços na luta contra o racismo a discriminação racial e o preconceito racial. Contudo, ainda existem dificuldades em assumir a questão racial como um problema real que necessita ser enfrentado pela sociedade brasileira. Enquanto esse processo de enfrentamento não ocorrer, as desigualdades sociais baseadas no racismo continuarão, e, com tendência ao acirramento, ainda mais quando se trata de igualdade de oportunidades.

Palavras-chave: raça; racismo; discriminação racial; classe; negro; preconceito. 


\section{Abstract}

The purpose of this paper is to conduct a bibliographical review in order to recover the classical-discussion about social class, race, ideology of the whitening/blackening and the issue of individual success. From the $70 \mathrm{~s}$ on, with the rising of the organized black movements, improvements in the struggle against racism and racial prejudice and discrimination occur. However, difficulties in assuming the racial issue as a real problem which needs to be faced by the Brazilian society, still exist. If this facing problem does not happen, the social differences based on racism will continue to exist and with a tendency to incitement, specially when it is concerned with equality of opportunities.

Key-words: race; racism; racial discrimination; class; black; prejudice. 